\title{
Early diastolic murmurs in end-stage renal failure
}

\author{
WILLIAM D. ALEXANDER' AND A. POLAK \\ From Wessex Regional Renal Unit, St. Mary's Hospital, Portsmouth, Hants
}

An early diastolic murmur thought to indicate functional aortic regurgitation was heard in 7 of 74 consecutive patients with end-stage renal failure assessed for chronic intermittent haemodialysis and transplantation. In all 7 cases the murmur was transient and related to episodes of hypertension and fluid overload and disappeared on correction of these factors. In a further 2 patients aortic regurgitation resulted from a structural abnormality of the aortic valve. Thus, an early diastolic murmur is not uncommon in this situation and does not necessarily indicate organic aortic valve disease which might preclude selection for haemodialysis and transplantation.

The causes of aortic regurgitation are many and are well reviewed by Runco and Booth (1963). Functional aortic regurgitation has been described as a rare occurrence in anaemia (Hunter, 1946) and congestive cardiac failure (McKusick, 1958). In hypertension the prevalence of functional aortic regurgitation has been reported as varying from 2 per cent (Paullin et al., 1927) to 9 per cent (Barlow and Kincaid Smith, 1960).

In end-stage renal failure, anaemia is invariable, hypertension is usual, and congestive cardiac failure not uncommon. There might, therefore, be expected to be a high incidence of functional aortic regurgitation in such patients, leading to errors in management, unless this is recognised as such (Matalon et al., 1971). We examined and followed up all patients referred to a Regional Renal Unit for assessment for haemodialysis over a two-year period to assess the incidence of aortic diastolic murmurs.

\section{Results}

The 74 patients studied were all those assessed as to their suitability for long-term haemodialysis and transplantation on account of end-stage renal failure. In the course of the study 9 were noted by at least 2 observers to have an early diastolic murmur. Two of these clearly had organic aortic valve disease: 1 had been investigated by cardiac catheterisation and a diagnosis of congenital aortic regurgitation made; the other developed aortic regurgitation in

'Present address: University Hospital of Wales, Cardiff, Wales. Received for publication 17 September 1976 the course of a staphylococcal septicaemia and died, necropsy revealing bacterial endocarditis involving the aortic valve. In the other 7 patients (see Table for details) the murmur was transient, suggesting that this was caused by functional aortic regurgitation.

A representative history is that of case 4 , a $24-$ year-old man first seen in 1967 complaining of headache. Physical examination showed a blood pressure of $220 / 130 \mathrm{mmHg}$, left ventricular hypertrophy, and grade 4 hypertensive retinopathy. He was treated with methyldopa $1 \mathrm{~g}$ t.d.s. Twelve months later he was admitted to the renal unit with increasing shortness of breath. He was then found to have a blood pressure of $200 / 110 \mathrm{mmHg}$ and grade 2 hypertensive retinopathy. Jugular venous pressure was raised $4 \mathrm{~cm}$ and there was mild peripheral oedema. On auscultation of the heart there was a soft systolic ejection murmur, a loud aortic valve closure sound, and an early diastolic murmur. Crepitations were heard at both lung bases. The electrocardiogram showed left ventricular hypertrophy, and the chest radiograph showed cardiomegaly and pulmonary oedema. Blood urea was $500 \mathrm{mg} / 100 \mathrm{ml}(83 \mathrm{mmol} / \mathrm{l})$. Peritoneal dialysis was performed and over the next three days he improved considerably: blood pressure fell to $170 / 100 \mathrm{mmHg}$, pulmonary and peripheral oedema cleared, and he lost $5 \mathrm{~kg}$ in weight; the early diastolic murmur disappeared. He was started on intermittent haemodialysis and methyldopa was continued. He remained well until 6 months later when he again became breathless. He was $5 \mathrm{~kg}$ above his estimated ideal weight and his blood pressure was $210 / 110 \mathrm{mmHg}$. 
Table Details of patients with end-stage chronic renal failure found to have an early diastolic murmur

\begin{tabular}{|c|c|c|c|c|c|c|c|}
\hline Case No. & $\begin{array}{l}\text { Age } \\
(y)\end{array}$ & Sex & Diagnosis & $\begin{array}{l}H b \\
(g / d l)\end{array}$ & $\begin{array}{l}\text { Lowest recorded } B P \text { when } \\
\text { murmour present }(\text { mmHg) }\end{array}$ & $\begin{array}{l}\text { Highest recorded } B P \text { when no } \\
\text { murmur present }(m \mathrm{mHg})\end{array}$ & $\begin{array}{l}\text { Evidence of fluid } \\
\text { overload }\end{array}$ \\
\hline $\begin{array}{l}1 \\
2 \\
3 \\
4 \\
5 \\
6 \\
7\end{array}$ & $\begin{array}{l}27 \\
24 \\
36 \\
28 \\
40 \\
16 \\
23\end{array}$ & $\begin{array}{l}\mathbf{M} \\
\mathbf{M} \\
\mathbf{F} \\
\mathbf{F} \\
\mathbf{M} \\
\mathbf{F} \\
\mathbf{M}\end{array}$ & $\begin{array}{l}\text { GN } \\
\text { GN } \\
\text { GN } \\
\text { GN } \\
\text { VUR } \\
\text { VUR } \\
\text { H/T after } \\
\text { pregnancy } \\
\text { toxaemia }\end{array}$ & $\begin{array}{l}6 \\
7 \\
6 \\
5 \\
6 \\
6 \\
6\end{array}$ & $\begin{array}{l}160 / 95 \\
176 / 110 \\
180 / 120 \\
160 / 90 \\
160 / 100 \\
140 / 80 \\
170 / 110\end{array}$ & $\begin{array}{l}220 / 140 \\
270 / 170 \\
200 / 130 \\
210 / 140 \\
210 / 115 \\
160 / 90 \\
200 / 150\end{array}$ & $\begin{array}{l}\text { PD } \\
\text { P } \\
\text { P } \\
\text { PD } \\
\text { PD } \\
\text { PD } \\
\text { PD }\end{array}$ \\
\hline
\end{tabular}

GN, glomerulonephritis; VUR, vesico-ureteric reflux; H/T, hypertension; $P$, pulmonary oedema; $D$, dependent oedema

He had peripheral and pulmonary oedema and again an early diastolic murmur was heard. His dialysis regimen was adjusted and his sodium and water intake restricted. He improved and the early diastolic murmur disappeared. Over the next 2 years he was admitted on 3 occasions, with shortness of breath and clinical and radiological evidence of pulmonary oedema. On each occasion he was well above his estimated ideal weight and a transient early diastolic murmur was heard; his blood pressure on these 3 occasions was $160 / 90,210 / 110$, and $180 / 95 \mathrm{mmHg}$. Since then he has had a successful renal transplant.

Details of the other patients can be seen in the Table. All were anaemic. All presented with symptoms suggesting fluid overload and were found to have dependent oedema and/or cardiac enlargement with pulmonary oedema on chest $x$-ray examination. Six were hypertensive at the time the murmur was heard, though in every case a higher blood pressure had been recorded at other times without a murmur being audible. In all cases the murmur disappeared after dialysis. Three patients had forearm arteriovenous shunts when the murmur was first heard (cases 1, 2, and 3). No patient had a history of rheumatic fever. All had negative serological tests for syphilis and sterile blood cultures. Cases 5 and 6 had been hypercalcaemic in the past; band keratopathy and ear drum calcification were present in cases 1,2 , and 3, and case 5 had severe peripheral vascular calcification.

Three patients have had successful transplants and 4 have died, case 3 from myocardial infarction, cases 5 and 6 from uraemia, and case 7 from septicaemia. Necropsy in cases 3 and 5 showed normal aortic valves.

\section{Discussion}

The early diastolic murmur in these patients was thought to be the result of aortic regurgitation and to be functional in 7 of the 9 . Pulmonary regurgita- tion was a possible alternative but was unlikely in the absence of any evidence of pulmonary hypertension.

All, except one, of the patients were hypertensive, though each had been seen at other times with a higher blood pressure but no murmur. This confirms the observation of Puchner et al. (1960) that functional aortic regurgitation in hypertension is not simply related to the height of the blood pressure. The incidence of functional aortic regurgitation in our patients $(9.5 \%)$ is higher than in most reported series of hypertensive patients (Paullin et al., 1927; Garvin, 1940; Puchner et al., 1960) though Barlow and Kincaid Smith (1960) found a 9 per cent incidence in their series of 100 patients at the Postgraduate Medical School of London. This also suggests that factors other than hypertension alone were responsible for the aortic regurgitation.

Fluid overload was present in all the patients and the murmur invariably disappeared when this was corrected. However, as commonly occurs in chronic renal failure, dialysis corrected the hypertension and fluid overload simultaneously; it is, therefore, difficult to judge the relative importance of these two factors. It seems likely that fluid overload was the major determinant, since symptoms of cardiac failure with shortness of breath and/or oedema were invariable presenting features and though hypertension was present it was not as severe as on previous occasions when there had been no aortic regurgitation. Anaemia is unlikely to have been an important factor since the murmurs disappeared without a rise in haemoglobin level. It may, however, have made it possible to detect some murmurs that would otherwise have been inaudible, as there is evidence that a low blood viscosity increases the intensity of murmurs (Garb, 1944).

We did not consider the presence of peripheral vascular calcification to be relevant since this is a common finding in end-stage renal failure and no aortic valve calcification was visible on chest $x$-ray films. It is interesting, however, that no fewer than 
3 patients had band keratopathy and ear-drum calcification, which are much less common complications of renal failure.

We conclude that there is a relatively high incidence of aortic regurgitation in patients with endstage renal failure; this is usually functional, occurring in the presence of fluid overload and hypertension, and is reversible by dialysis.

We thank Professor H. A. Lee for permission to include patients under his care, Dr. J. Burston for the necropsy examinations, and Dr. D. W. Barritt for helpful advice.

\section{References}

Barlow, J., and Kincaid Smith, P. (1960). Auscultatory findings in hypertension. British Heart fournal, 22, 505-514.

Garb, S. (1944). The relationship of blood viscosity to the intensity of heart murmurs. American Heart fournal, 28, 568-573.
Garvin, C. F. (1940). Functional aortic insufficiency. Annals of Internal Medicine, 13, 1799-1804.

Hunter, A. (1946). The heart in anaemia. Quarterly fournal of Medicine, 15, 107-124.

McKusick, V. A. (1958). Cardiovascular Sound in Health and Disease. Williams and Wilkins, Baltimore.

Matalon, R., Moussalli, A. R. J., Nidus, B. D., Katz, L. A., and Eisinger, R. P. (1971). Functional aortic insufficiencya feature of renal failure. New England fournal of Medicine, 285, 1522-1523.

Paullin, J. E., Bowcock, H. M., and Wood, R. H. (1927). Complications of hypertension. American Heart fournal, 2 , 613-617.

Puchner, T. C., Huston, J. H., and Hellmuth, G. A. (1960). Aortic valve insufficiency in arterial hypertension. American fournal of Cardiology, 5, 758-760.

Runco, V., and Booth, R. W. (1963). Basal diastolic murmurs. American Heart Fournal, 65, 697-708.

Requests for reprints to Dr. W. D. Alexander, Department of Medicine, University Hospital of Wales, Heath Park, Cardiff, Wales. 